\title{
Liver transplantation in a child with acute liver failure resulting from drug rash with eosinophilia and systemic symptoms syndrome
}

\author{
Seung Min Song, MD', Min Sung Cho, MD', Seak Hee Oh, MD', Kyung Mo Kim, MD', Young Seo Park, MD', Dae Yeon Kim, MD²,
} Sung Gyu Lee, $\mathrm{MD}^{3}$

Departments of ${ }^{1}$ Pediatrics and ${ }^{2}$ Pediatric Surgery, Asan Medical Center Children's Hospital, University of Ulsan College of Medicine, Seoul

${ }^{3}$ Department of Surgery, Asan Medical Center, University of Ulsan College of Medicine, Seoul, Korea

Drug rash with eosinophilia and systemic symptoms (DRESS) syndrome is characterized by a severe idiosyncratic reaction including rash and fever, often with associated hepatitis, arthralgias, lymph node enlargement, or hematologic abnormalities. The mortality rate is approximately $10 \%$, primarily owing to liver failure with massive or multiple disseminated focal necrosis. Here, we report a case of a 14 -year-old girl treated with vancomycin because of a wound infection by methicillin-resistant Staphylococcus aureus, who presented with non-specific symptoms, which progressed to acute liver failure, displaying the hallmarks of DRESS syndrome. With the presence of aggravated hepatic encephalopathy and azotemia, the patient was refractory to medical treatments, she received a living-donor liver transplantation, and a cure was achieved without any sign of recurrence. Vancomycin can be a cause of DRESS syndrome. A high index of suspicion and rapid diagnosis are necessary not to miss this potentially lethal disease.

Key words: DRESS syndrome, Vancomycin, Acute liver failure, Liver transplantation

\section{Introduction}

The hypersensitivity syndrome, described as drug rash with eosinophilia and systemic symptoms (DRESS) syndrome is a severe, acute, drug reaction, defined by the presence of fever, cutaneous eruption, and systemic findings including enlarged lymph nodes, hepatitis, or hematologic abnormalities with eosinophilia and atypical lymphocytes ${ }^{1,2)}$. The syndrome can involve several sites, leading to findings such as pneumonitis, renal failure, myocarditis, thyroiditis, or neurologic symptoms, but the liver is the most commonly affected internal organ ${ }^{3}$. This reaction can be life threatening, with a mortality rate of approximately 10\%, most commonly secondary to liver failure ${ }^{1)}$. Here we report the first pediatric case of liver transplantation for the treatment of acute liver failure caused by vancomycin-induced DRESS syndrome in Korea.

\section{Case report}

A 14-year-old girl was referred to Asan Medical Center Children's Hospital on the basis of test results that indicated abnormal liver function. She had been injured by a traffic accident 10 years earlier, and had undergone plastic surgery twice to heal wounds on her forehead. The second procedure included a free flap operation and
Corresponding author: Kyung Mo Kim, MD Department of Pediatrics, Asan Medical Center Children's Hospital, University of Ulsan College of Medicine, 88 Olympic-ro 43-gil, Songpa-gu, Seoul 138-736, Korea

Tel: +82-2-3010-3380

Fax: +82-2-473-3725

E-mail: kmkim@amc.seoul.kr

Received: 21 July 2012

Revised: 28 September 2012

Accepted: 29 November 2012

Copyright $@ 2013$ by The Korean Pediatric Society

This is an open-access article distributed under the terms of the Creative Commons Attribution NonCommercial License (http://creativecommons.org/ licenses/by-nc/3.0/) which permits unrestricted noncommercial use, distribution, and reproduction in any medium, provided the original work is properly cited. 
craniectomy. Thereafter she had suffered from methicillinresistant Staphylococcus aureus (MRSA) osteomyelitis, which had been treated with intravenous vancomycin over five weeks. Following this treatment, she developed fever and whole-body pruritic erythema, and abnormal liver function tests 6 days prior to her transfer. On admission, she presented with fever, nausea, vomiting, and abdominal discomfort. A generalized erythematous rash with variously sized, discrete lesions was noted on the face, trunk, and extremities. The patient reported an itching and heating sensation, which was aggravated after vancomycin injection. Marked hepatomegaly was also observed.

Laboratory tests showed a total eosinophil count of 3,150/ $\mathrm{mm}^{3}$ (normal, $<500 \mathrm{~mm}^{3}$ ), C-reactive protein level of $15.1 \mathrm{mg} / \mathrm{dL}$ (normal, $<0.6 \mathrm{mg} / \mathrm{dL}$ ), creatinine level of $2.5 \mathrm{mg} / \mathrm{dL}$ (normal, 0.7 to $1.4 \mathrm{mg} / \mathrm{dL}$ ), aspartate aminotransferase (AST) level of $320 \mathrm{IU} / \mathrm{L}$ (normal, $<5$ to $40 \mathrm{IU} / \mathrm{L}$ ), alanine aminotransferase (ALT) level of 263 $\mathrm{IU} / \mathrm{L}$ (normal, $<5$ to $40 \mathrm{IU} / \mathrm{L}$ ), alkaline phosphatase level of 440 $\mathrm{IU} / \mathrm{L}$ (normal, 40 to $120 \mathrm{IU} / \mathrm{L}$ ), gamma glutamyl transpeptidase level of $321 \mathrm{IU} / \mathrm{L}$ (normal, 8 to $35 \mathrm{IU} / \mathrm{L}$ ), lactate dehydrogenase level of 2,437 IU/L (normal, 120 to $250 \mathrm{IU} / \mathrm{L}$ ), total bilirubin level of $3.3 \mathrm{mg} / \mathrm{dL}$ (normal, 0.2 to $1.2 \mathrm{mg} / \mathrm{dL}$ ), direct bilirubin level of $1.8 \mathrm{mg} / \mathrm{dL}$ (normal, $<0.5 \mathrm{mg} / \mathrm{dL}$ ), prothrombin time (PT) international normalized ratio (INR) of 1.68 (normal, 0.8 to 1.3), and activated partial thromboplastin time of 34.5 (normal, 25 to 35).

Serologic tests for hepatitis A, B, and C, as well as cytomegalovirus, Epstein-Barr virus, and autoimmune hepatitis were all negative. Screens for drugs, such as acetaminophen, were negative. The vancomycin level was $26.9 \mathrm{mg} / \mathrm{L}$ (normal, 20 to $40 \mathrm{mg} / \mathrm{L}$ ). Treatment with vancomycin was stopped, and replaced with ciprofloxacin for the treatment of osteomyelitis. Intravenous delivery of a high dose of methylprednisolone was initiated upon an initial suspicion of DRESS syndrome. However, her liver function worsened progressively on hospital day 7, with an AST level of 1,285 IU/L, ALT level of 1,077 IU/L, total bilirubin level of $15.5 \mathrm{mg} / \mathrm{dL}$, direct bilirubin level of $8.0 \mathrm{mg} /$ $\mathrm{dL}$, and PT INR of 4.8, all suggesting acute liver failure. Given the presence of aggravated hepatic encephalopathy, azotemia, and that the patient was refractory to medical treatments, she received a living-donor liver transplantation from her aunt on hospital day 9. The detailed care of preliver and postliver transplantation and care of acute liver failure in our program was described elsewhere ${ }^{4,5}$.

After liver transplantation, the skin rash disappeared, with normalization of the eosinophil count and scores in liver and renal function tests. No severe clinical and surgical complications developed postoperatively. Serial liver biopsies showed no evidence of acute rejection. Over the course of a 25-month follow-up period, there has not been any definite recurrence of DRESS syndrome, with the exception of persistently elevated levels of liver enzymes and intermittent eosinophilia. The patient is currently suffering from iatrogenic Cushing's syndrome owing to the high dose of steroids administered to control her elevated levels of liver enzymes.

\section{Discussion}

We here report a pediatric case of acute liver failure resulting from DRESS syndrome, which was treated by liver transplantation. Many adult cases of DRESS syndrome have been reported in Korea ${ }^{6,7)}$. However, no pediatric case has been reported yet. Most reported cases of DRESS syndrome show that a cure can be achieved by the immediate withdrawal of the causative agent and the administration of methylprednisolone ${ }^{6}$. Liver involvement in DRESS syndrome is common and may range from a transitory increase in liver enzymes to liver necrosis with acute liver failure. To our knowledge, acute liver failure caused by DRESS syndrome has been reported at least twice in other European countries ${ }^{8,9)}$. In one of these cases ${ }^{99}$, the patient died waiting for a liver transplant, whereas in the other case ${ }^{8)}$, fatal recurrence occurred after liver transplantation despite potent immunosuppression and cessation of the precipitating factors.

The pathogenesis of DRESS syndrome is not fully understood, and may be multifactorial ${ }^{10)}$. Although it is most commonly associated with antiepileptic drugs, DRESS syndrome has also been reported after exposure to a range of medications, including sulfasalazine, doxycycline, allopurinol, linezolid, and vancomycin ${ }^{1,8,10)}$. DRESS syndrome can persist or even be aggravated after elimination of the precipitating agent. The differential diagnosis includes Stevens-Johnson syndrome (SJS), life-threatening, cutaneous adverse reaction. Precise diagnostic boundaries between SJS and DRESS have not been well established. The two syndromes overlap clinically, but have different characteristics, treatments and prognoses ${ }^{111}$.

Therefore, a high index of suspicion and rapid diagnosis may be necessary to save the patient's life. The only undisputed way to treat DRESS syndrome involves withdrawal of the drug suspected to be responsible. The use of systemic corticosteroids is common, although evidence regarding their effectiveness is scant ${ }^{12)}$. In our case, we replaced vancomycin with ciprofloxacin approximately 6 days after symptoms of DRESS syndrome were evident, and immediately began corticosteroid treatments after the switch to ciprofloxacin therapy. Although ciprofloxacin is also known to cause DRESS ${ }^{13)}$, we finally chose that agent to control infection because other several antibiotics aggravated skin rash as well. These measures were ineffective in preventing liver failure.

To our knowledge, this is the first pediatric case report to describe vancomycin-induced acute liver failure occurring as a component of the DRESS syndrome in Korea. We highlight 
the need for awareness of the association between drugs, DRESS syndrome and liver failure. Given the absence of reports describing the outcomes of liver transplantation in patients with DRESS syndrome, particular attention should be devoted to identification of its possible recurrence after liver transplantation.

\section{Conflict of interest}

No potential conflict of interest relevant to this article was reported.

\section{References}

1. Bocquet H, Bagot M, Roujeau JC. Drug-induced pseudolymphoma and drug hypersensitivity syndrome (drug rash with eosinophilia and systemic symptoms: DRESS). Semin Cutan Med Surg 1996; 15:250-7.

2. Sparsa A, Loustaud-Ratti V, Mousset-Hovaere M, De Vencay P, Le Brun V, Liozon E, et al. Drug-induced hypersensitivity syndrome in internal medicine: diagnostic and therapeutic traps. Eight observations. Rev Med Interne 2000;21:1052-9.

3. Eshki M, Allanore L, Musette P, Milpied B, Grange A, Guillaume JC, et al. Twelve-year analysis of severe cases of drug reaction with eosinophilia and systemic symptoms: a cause of unpredictable multiorgan failure. Arch Dermatol 2009;145:67-72.
4. Oh SH, Kim KM, Kim DY, Lee YJ, Rhee KW, Jang JY, et al. Longterm outcomes of pediatric living donor liver transplantation at a single institution. Pediatr Transplant 2010;14:870-8.

5. Oh SH, Kim KM, Kim KY, Lee YJ, Lee SG. Clinical experience of liver transplantation in children with acute liver failure [abstract \#0-94]. In: 2011 Joint International Congress of ILTS, ELITA, \& LICAGE; 2011 Jun 22-25; Valencia, Spain. Mount Laurel: International Liver Transplantation Society; 2011.

6. Kim DH, Kim IS, Park J, Yoo KH, Park KY, Li K, et al. A case of carbamazepine-induced DRESS syndrome. Korean J Asthma Allergy Clin Immunol 2011;31:59-62.

7. Jeon EK, Lee KM, Kwon YB, Seo YJ, Park JK, Lee JH. Three cases of allopurinol-induced DRESS syndrome. Korean J Dermatol 2007;45:714-9.

8. Mennicke M, Zawodniak A, Keller M, Wilkens L, Yawalkar N, Stickel F, et al. Fulminant liver failure after vancomycin in a sulfasalazine-induced DRESS syndrome: fatal recurrence after liver transplantation. Am J Transplant 2009;9:2197-202.

9. Syn WK, Naisbitt DJ, Holt AP, Pirmohamed M, Mutimer DJ. Carbamazepine-induced acute liver failure as part of the DRESS syndrome. Int J Clin Pract 2005;59:988-91.

10. Vauthey L, Uckay I, Abrassart S, Bernard L, Assal M, Ferry T, et al. Vancomycin-induced DRESS syndrome in a female patient. Pharmacology 2008;82:138-41.

11. Jeung YJ, Lee JY, Oh MJ, Choi DC, Lee BJ. Comparison of the causes and clinical features of drug rash with eosinophilia and systemic symptoms and Stevens-Johnson syndrome. Allergy Asthma Immunol Res 2010;2:123-6.

12. Roujeau JC, Stern RS. Severe adverse cutaneous reactions to drugs. N Engl J Med 1994;331:1272-85.

13. Artukovic M, Kustelega J, Lugovic-Mihic L. DRESS syndrome with mild manifestations as a diagnostic and therapeutic problem: case report. Acta Clin Croat 2010;49:479-84. 